\title{
Um Oásis Urbano: Dois Estudos das Interações Pessoa-Ambiente na Praça Kalina Maia, Natal/RN
}

\author{
Cíntia Camila Liberalino Viegas \\ Eduardo Alexandre Ribeiro da Silva \\ Gleice Azambuja Elali \\ Universidade Federal do Rio Grande do Norte \\ Natal, RN, Brasil
}

\begin{abstract}
RESUMO
Embora vários fatores apontem seu atual abandono, as praças influenciam a qualidade de vida das cidades, colaborando com o microclima urbano e a restauração do equilíbrio físico/mental das pessoas. Esse artigo apresenta duas pesquisas (independentes) embasadas na literatura de Psicologia Ambiental, realizadas na Praça Kalina Maia (Natal/RN), visando compreender seu uso: uma abordou atividades de lazer; outra, a socialização de idosos. Em cada estudo, o método somou diário de campo, entrevistas e observação comportamental (mapeamento ou naturalística). Os resultados revelam a setorização de usos, mostrando que, durante o dia, idosos, adultos, adolescentes e crianças ali desenvolvem várias atividades, sobretudo esportivas - que predominam na ATI (onde se concentram os idosos). Conclui-se que, se existirem condições de suporte às atividades de lazer, as praças ainda podem ser oásis urbanos, promovendo lazer e socialização, conhecimento que pode contribuir para a proposta de programas que incentivem seu uso e retroalimentem seu projeto.
\end{abstract}

Palavras-chave: Psicologia Ambiental; praça; lazer; socialização de idosos; observação comportamental.

\section{ABSTRACT}

\section{An Urban Oasis: Two Studies of People-Environmental Interactions in Kalina Maia Square, Natal/RN}

Although several factors point to their current abandonment, public squares influence the quality of life in cities, contributing to urban microclimate and restoring people physical/mental equilibrium. This article presents two (independents) studies based on literature from Environmental Psychology and performed at the Kalina Maia Square (Natal/RN) in order to understand its use: one studied leisure activities; another, the socialization of elderly. In each study, field diary, interviews and behavioral observation (mapping or naturalistic) were used. The results revealed the use sectorization, showing, during the day, the presence of elderly, adults, teenagers and children that carry out several activities, especially sports - that predominate in ATI (where elderly area concentrated). We noted that if conditions are provided to support people leisure activities, public squares can still be urban oasis, promoting leisure and socialization. These findings can contribute to propose programs that encourage the use of these places and have influence in their design.

Keywords: Environmental Psychology; public square; leisure; elderly socialization; behavioral observation.

\section{RESUMEN}

Un Oasis Urbano: Dos Estudios de las Interacciones Persona-Medio Ambiente en la Plaza Kalina Maia, Natal/RN Aunque varios factores señalen su abandono actual, las plazas influyen en la calidad de vida en las ciudades, ayudan el microclima urbano y restauran el equilibrio físico/mental de las personas. Este artículo presenta dos estudios (independientes) basados en la literatura de la Psicología Ambiental y llevados a cabo en la Plaza Kalina Maia (Natal/RN) interesados en la comprensión de su uso: uno dirigido a las actividades de ocio; otro, a la socialización de los ancianos. En cada estudio, el método incluye diario de campo, entrevistas y observación del comportamiento (mapeo o naturalista). Los resultados revelan la sectorización de usos y muestran, durante el día, la presencia de ancianos, adultos, adolescentes y niños, los cuales realizan variadas actividades, especialmente deportivas - que predominan en ATI (donde los ancianos se concentran). Nos damos cuenta de que, si se dan las condiciones para apoyar las actividades de ocio, las plazas pueden seguir siendo oasis urbanos, promoviendo el ocio y socialización, conocimiento que puede contribuir a proponer programas para fomentar su uso y influenciar su proyecto.

Palabras clave: Psicología Ambiental; plaza; ocio; socialización de los ancianos; observación del comportamiento. 


\section{INTRODUÇÃO}

Correspondendo às áreas não ocupadas por edificações ou pelo sistema viário, situados em contexto urbano, os espaços livres públicos (ELPs) - também mencionados na literatura como "open spaces" - estão relacionados ao conjunto formado por calçadas, praças, largos, parques, terrenos baldios e similares. Historicamente os ELPs passaram por inúmeras transformações morfológicas e funcionais, ajustando-se às diversas maneiras de se usar, pensar, perceber e planejar o ambiente sociofísico das cidades, de modo que sua contínua ressignificação se relaciona às diferentes formas de apropriação e relações interpessoais que refletem valores vigentes da sociedade em cada momento sociohistórico. Embora em geral os ELPs tenham sido associados ao convívio e lazer, manifestações políticas, artísticas e sociais, na atualidade, as desigualdades socioeconômicas, a violência e a carência de suporte ambiental se refletem em denúncias sobre vandalismo e insegurança. Esse quadro alimenta o discurso sobre seu esvaziamento, ampliado pelo surgimento dos shoppings centers e sua promessa de reunir lojas, serviços e atrações culturais em espaços fechados dotados de conforto e segurança (Alex, 2008; Andrade, 2009; Gomes, 2007; Silva, Lopes \& Lopes, 2009).

Sob outra perspectiva, a literatura no campo da Psicologia Ambiental ressalta a importância do ser humano usufruir de áreas não construídas para manter seu equilíbrio físico e mental, em especial as que permitem contato com a natureza, que, além de produzirem afastamento dos estressores urbanos, alimentam o simbolismo, a liberdade e o prazer, funcionando como ambientes restauradores da saúde (Gehl, 2007; Kaplan; Kaplan \& Ryan, 1998; Korpela et al., 2010; Ryan et al., 2010; Thompson, 2007). Diante desse tipo de argumento, pesquisadores de diversos países têm desenvolvido investigações voltadas para a compreensão e a melhoria dos ELPs, analisando aspectos como condições de conforto, ergonomia, segurança, relações morfológicas/tipológicas e as várias modalidades de interações pessoa-ambiente que ali acontecem (embora, diante das demais, estas últimas ainda sejam pouco exploradas).

Os resultados dessas pesquisas mostram que a frequência aos ELPs incentiva a prática de atividades físicas e favorece a adoção de um estilo de vida ativo e saudável (Hino et al., 2010; Petroski, Silva, Reis \& Pelegrini, 2009; Sugiyama \& Thompson, 2005), benefícios associados às oportunidades que o ambiente oferece como suporte para diferentes atividades. As pesquisas que exploraram o suporte ambiental se baseiam na ideia de encaixe pessoaambiente (environment-fit), que reflete a congruência entre a demanda do ambiente (pressão ambiental) e a competência pessoal (Sugiyama \& Thompson, 2005). Em geral, o suporte ambiental influencia o padrão de atividades externas das pessoas, em conformidade com suas diferentes capacidades funcionais e estilos de vida, sendo esperável que o uso dos ELPs varie em função dos projetos, faixas etárias, possibilidades e limitações de seus usuários.

Contribuindo para essa discussão no contexto da cidade brasileira, alguns estudos realizados no Grupo de Estudos Inter-Ações Pessoa-Ambiente (GEPA/UFRN) tem se dedicado aos ELPs, especialmente praças. Este artigo sintetiza os principais resultados de dois trabalhos realizados na Praça Kalina Maia (Natal $\mathrm{RN}$ ), escolhidos porque se complementam: (i) uma pesquisa de mestrado (Liberalino, 2011), cujo objetivo foi compreender sua ocupação para atividades de lazer; (ii) um dos estudos de caso que subsidiaram uma tese de doutorado (Silva, 2014), que investigou a importância de praças para a socialização de idosos. Ao promover uma discussão conjunta destes trabalhos, o artigo reflete sobre o potencial da praça como oásis no meio urbano e, consequentemente, sobre as condições de sustentabilidade dos espaços públicos. Tais trabalhos, independentes entre si, atenderam às exigências da ética na pesquisa e adotaram estratégias multimetodológicas (Günther; Elali \& Pinheiro, 2011; Sommer \& Sommer, 2002) abrangendo: registros em diário de campo, entrevistas e observação comportamental (no primeiro caso, por mapeamento; no segundo, naturalística).

A PKM foi escolhida por: estar localizada em área de uso misto, embora predominantemente residencial (não sendo apenas "local de passagem"); ter um desenho contemporâneo que favorece o uso; possuir elementos de suporte para permanência e realização de atividades de lazer, notadamente a "Academia da Terceira Idade" (ATI); estar em bom estado de conservação.

Para apresentar o trabalho realizado esse artigo foi subdividido em quatro subitens: inicialmente, são comentadas as bases teórico-conceituais comuns aos estudos; seguem-se a apresentação (isolada) de cada pesquisa, em termos de método e principais resultados; depois tais resultados são discutidos conjuntamente.

\section{PRAÇA: LUGAR DE LAZER E SOCIALIZAÇÃO}

Correspondendo a atividades gratuitas, prazerosas e voluntárias, as quais a pessoa se dedica quando dispõe de um tempo não ocupado com atividades formais e pode exercitar livremente suas alternativas de ação 
ou participação (Camargo, 2008), o lazer se configura como uma escolha pessoal, porém mediada por elementos de natureza sociocultural que o oportunizam ou valorizam uma escolha em detrimento de outras. Nossas cidades oferecem várias oportunidades para 0 desenvolvimento desse tipo de atividade, em especial os ELPs, pois, como são áreas cujo acesso é irrestrito e universal, neles há mais oportunidades para trocas afetivas, sociais e culturais (Active Living Research, 2010; OPENspace Research Centre, 2010; Thompson \& Travlou, 2007; Woolley, 2005). Para isso também contribui a presença de elementos naturais, sobretudo de vegetação, que tem influencia no microclima urbano (mediante a amenização da temperatura, o aumento da umidade relativa do ar e da absorção de poluentes) e favorece psicologicamente o bem-estar humano (IDGO, 2010), inclusive quanto à promoção do relacionamento interpessoal. A possibilidade de abrigar práticas sociais variadas, desde momentos individuais de descontração até manifestações de vida urbana e comunitária (Oliveira \& Mascaró, 2007), torna tais locais campo fértil para os estudos relativos às diversas fases do desenvolvimento humano, das crianças (Cotrim \& Bichara, 2013; Luz \& Kuhnen, 2013) aos idosos (Sugiyama \& Thompson, 2005; Sugiyama, Thompson, \& Alves, 2009).

No contexto dos ELPs as praças são, por definição, espaços públicos abertos situados em área urbana, configurando-se como locais de lazer e convívio "acessíveis aos cidadãos e livres de veículos" (Robba \& Macedo, 2003, p. 17). Elas se caracterizam pelos valores ambientais, funcionais, estéticos e simbólicos, correspondendo a arranjos complexos de limitações e exigências relativas ao ambiente físico/geográfico, legislativo/normativo, projetual e comportamental, direta ou indiretamente relacionados aos usos que ali ocorrem, e que marcam a dinâmica do conjunto urbano em que se inserem. Atribuir à praça a condição de "espaço público" e "local de lazer" significa reconhecê-la como uma categoria específica entre os ELPs e, ao mesmo tempo, reafirmar sua função de mesclar usos e grupos sociais diferenciados (Gomes, 2007). De acordo com essas condições, cada praça assume singularidades histórico-culturais, o que define um processo no qual se criam identidades entre as pessoas e o espaço público (Mourão \& Cavalcante, 2011) capazes de desencadear seu uso efetivo e torná-la "lugar" (Tuan, 1983) para quem dela usufrui.

Segundo Jacobs (1961), o sucesso das praças localizadas em áreas residenciais está atrelado à diversidade de funções que oferecem e à multiplicidade de horários para seu uso. Em direção semelhante, Alex (2008) mostrou que as áreas acessíveis e adaptáveis das praças são as mais frequentemente ocupadas, assumindo o papel de favorecer a fuga da rotina diária, satisfazer aspirações individuais (descanso, esporte, etc.), promover o contato entre estranhos, estimular atividades variadas no entorno e, sobretudo, consolidar a presença e a permanência das pessoas no lugar. Tais argumentos nos permitem reafirmar a praça enquanto espaço essencial à vitalidade e à sustentabilidade urbana (Mira \& Dumitru, 2014), com enorme potencial para influenciar a qualidade de vida da população, justificando nosso interesse por estudá-las.

\section{ESTUDO 1 - O LAZER NA PRAÇA KALINA MAIA}

Com objetivo mais descritivo, o primeiro estudo (Liberalino, 2011) analisa o uso da PKM como lugar de lazer, nas modalidades contemplativo, ativo, cultural e esportivo (Robba \& Macedo, 2003), além de identificar novas modalidades que, embora não se enquadrem nestas categorias, se mostraram importantes naquele contexto, como é o caso de conversar, namorar, telefonar e negociar.

\section{Método}

A investigação associou observação comportamental (mapeamento e análise de vestígios comportamentais), entrevistas e diário de campo da pesquisadora. Ela aconteceu em duas fases: na primeira (observação) não houve interação verbal entre a pesquisadora e os usuários, a fim de evitar alterações comportamentais dela decorrentes; a segunda fase, correspondente às entrevistas, aconteceu após assinatura do Termo de Consentimento Livre e Esclarecido (TCLE) pelos entrevistados.

Como um tipo de observação sistemática, o Mapeamento Comportamental (Pinheiro; Elali \& Fernandes, 2008; Sommer \& Sommer, 2002) permite a representação gráfica das localizações das pessoas no espaço, baseando-se no registro de suas atividades em determinado tempo e lugar, sendo desenvolvido em dois procedimentos: Mapeamento Comportamental Centrado no Lugar (MCCLugar) e Mapeamento Comportamental Centrado na Pessoa (MCCPessoa). O primeiro verifica o que acontece e onde as pessoas se dispõem; o segundo identifica os movimentos e atividades de pessoas específicas, incluindo o tempo neles usado.

No MCCLugar os registros aconteceram de $15 \mathrm{em}$ 15 minutos e a ficha de observação foi definida de acordo com os comportamentos verificados informalmente, agrupados nas categorias de lazer já indicadas. O espaço foi subdividido em 12 setores (Figura 1), em função das suas características físicas e comportamentais, acompanhando a setorização insinuada pelos equipamentos e mobiliário presentes. 

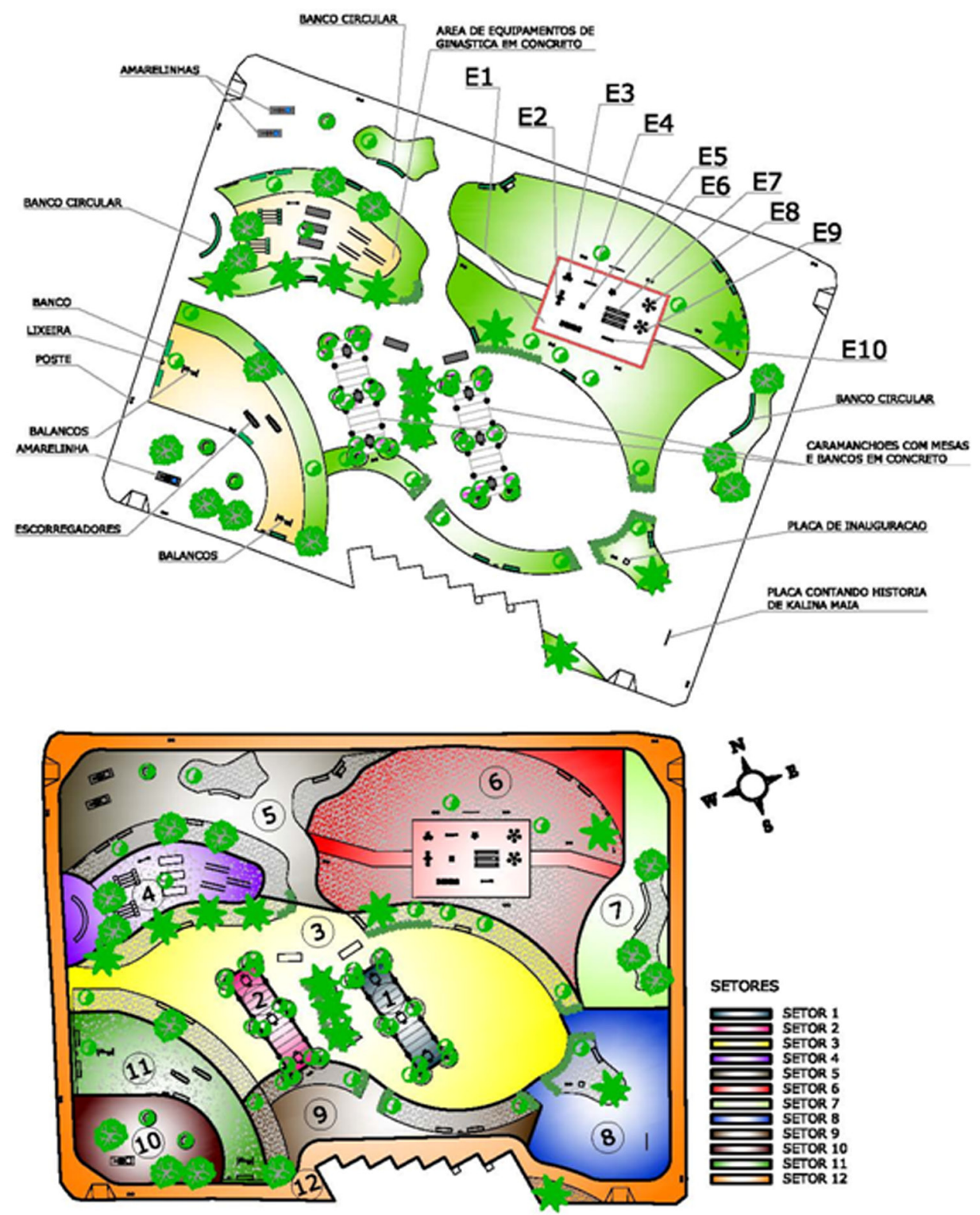

Figura 1. Planta Baixa e Divisão dos Setores da Praça Kalina Maia.

- Setor 1 (St1): Situado na região central, é composto por caramanchão em concreto, coberto por bouganvilles, e possui 3 conjuntos de mesa e 2 bancos em concreto.

- Setor 2 (St2): Semelhante ao Setor 1.

- Setor 3 (St3): Área central da praça, possui muito espaço livre, alguns canteiros e bancos.

- Setor 4 (St4): Recebe os equipamentos tradicionais de ginástica, em concreto, circundada por uma faixa de grama com bancos.

- Setor 5 (St5): Localizado em uma das extremidades da praça, possui bancos curvos e tradicionais e 2 amarelinhas.

- Setor 6 (St6): Contém a "Academia da Terceira Idade" e bancos (foi alvo do Estudo 2).

- Setor 7 (St7): Região mais sombreada da praça; possui bancos curvos e tradicionais.
- Setor 8 (St8): Tem canteiro curvo, um banco tradicional e duas placas (a da inauguração e outra, que conta a história da Praça Kalina Maia).

- Setor 9 (St9): Próximo ao estacionamento, em porção central da praça, possui canteiros curvos com bancos tradicionais.

- Setor 10 (St10): Região próxima ao playground, marcada pelos bancos circulares e jogo de "amarelinha" pintado no piso.

- Setor 11 (St11): Contém playground com equipamentos em concreto dispostos sobre areia, circundada por faixa gramada; tem formato curvo e bancos.

- Setor 12 (St12): Setor livre e pavimentado que define o contorno da PKM (equivalente à calçada externa), onde predominam circulação/passagem, corrida ou caminhada. 
Após pré-teste e testes de confiabilidade, a pesquisadora realizou três meses de observação (3 horas diárias), a fim de preencher todos os horários dos sete dias da semana no período das 5:00h às 20:00h, configurando uma "semana típica de ocupação". O MCCPessoa complementou o MCCLugar, registrando (em detalhes e individualmente) o uso do local por 50 pessoas, seu percurso (desenho), principais atividades e tempo para desenvolvê-las. Os participantes foram escolhidos aleatoriamente, porém, procurando equilíbrio de quantidades quanto ao sexo, idade e horário de frequência ao local.

A análise de vestígios comportamentais (Pinheiro; Elali \& Fernandes, 2008; Sommer \& Sommer, 2002) permitiu a identificação de usos não observados diretamente, tendo recorrido a fotografias. Ampliando a compreensão das informações coletadas foram realizadas entrevistas semiestruturadas (Günther, 2008) com os usuários, que aconteceram na PKM a fim de promover o melhor acesso a sua imagem mental do lugar, o resgate de lembranças e o desenvolvimento de um olhar mais acurado sobre o passado e o presente.

\section{Principais resultados}

O MCCLugar (Figura 2) confirmou a vitalidade da PKM, uma vez que, de modo geral, constatou a diversidade de sua utilização para atividades de lazer, variável em função dos dias da semana e dos horários, contribuindo para a sustentabilidade urbana (Mira \& Dumitru, 2014). Embora se verifique presença de usuários de várias idades durante praticamente todo o dia, o fluxo de pessoas é maior no início da manhã e no final da tarde.

No início da manhã (a partir das 5 horas) há maior quantidade de adultos e idosos, realizando atividades físicas (ginástica, corrida e caminhada). Antes das 8:00h adultos e adolescentes utilizam o espaço como passagem, a caminho do trabalho ou da escola. Idosos que moram na residência geriátrica próxima costumam utilizar a praça para exercícios (maior uso) e contemplação. Muitos possuem limitações físicas e sentam em cadeiras de balanço ou rodas trazidas para o local, ocupando o St7, onde fica a árvore com a maior copa da praça, que proporciona grande sombreamento pela manhã. Neste sentido, a PKM oferece condições ambientais que favorecem o desenvolvimento humano, contribuindo, em especial, para a qualidade de vida dos idosos (Sugiyama, Thompson, \& Alves, 2009). Entre 10 e 14 horas, o sombreamento e o movimento diminuem consideravelmente. Mesmo em condições de conforto/sombreamento menos adequadas, ao saírem da escola, crianças e adolescentes conversam e/ou namoram sob as poucas sombras (St1, St2, St7 e
St10) ou brincam nos equipamentos de ginástica (St6). Atravessando a praça antes ou depois das aulas, estes estudantes são responsáveis pelo aumento do fluxo de passantes pelo local.

Após 16h a PKM mostra seu maior movimento, frequentada por pessoas de todas as idades. Crianças brincam no playground (St11) e equipamentos da ATI (St6), e usam todos os setores para atividades dinâmicas. Adolescentes e adultos conversam, namoram e se exercitam na ATI ou na calçada circundante (caminhada/corrida). Embora em número menor do que no início da manhã, os idosos também se exercitam; alguns frequentam o local nos dois períodos, passando parte do tempo em conversas ou contemplação. À noite o movimento diminui, porém as atividades permanecem semelhantes às dos períodos anteriores. Nos domingos a quantidade de adultos e idosos praticando exercícios físicos é menor do que em outros dias e suas atividades são iniciadas mais tarde.

Embora os diversos grupos etários não se misturem muito, de modo geral há alguma interação, pacífica e desejável, entre eles, alguns dos quais formados por famílias. Uma exceção nesse clima social positivo é o conflito entre idosos e jovens praticantes de esportes mais radicais (skate, le parkour e similares) que, com suas manobras, invadem (mesmo involuntariamente) o espaço pessoal dos mais velhos e geram sentimento de insegurança (medo de serem "atropelados").

O lazer contemplativo muitas vezes ocorre após a prática de exercícios e predomina nos St3 e St10, associado à presença de elementos de suporte como bancos, sombra e a oportunidade para observar outras pessoas. No St3, os caramanchões revestidos por trepadeiras e contendo mesas e bancos são bastante requisitados. No St10 as pessoas descansam, deitam e supervisionam crianças que brincam no playground (St11).

As brincadeiras se destacam nos St3, St11 e, sobretudo, no St6. As atividades dinâmicas como futebol, patins, skate e corre-corre, acontecem no St3. No St11 prevalece o playground (balanço e escorregador), utilizado não apenas pelas crianças, mas também pelos adolescentes. No St6, a ATI, destinada aos idosos, muitas vezes se transforma no brinquedo preferido dos jovens.

O lazer esportivo é bem setorizado, concentrado nos St6 (ATI) e St12 (perímetro). A prática esportiva foi o comportamento mais mapeado ( $40 \%$ a $49,9 \%$ dos registros efetuados), enquanto o lazer cultural foi o menos verificado (menos de 10\% dos registros), se relacionando aos St1 e St3: as mesas e bancos do primeiro são usados para desenho, leitura, estudo e até hip hop; no segundo, cuja configuração espacial permite multiuso, o hip hop predomina. 
Conversa e namoro, entendidos como atividades associativas (Dumazedier, 2004), acontecem em quase todos os setores da PKM, em especial quando existem bancos (St1, St3 e St5) e equipamentos para exercícios (St6 e St12). O namoro foi registrado nos St1, St2, St5, St7, St10 e St11, muitas vezes sugerindo busca por maior privacidade em relação a outras pessoas.

O MCCPessoa gerou mapas de percursos que permitem a rápida visualização da ocupação da praça (Figura 2). Foram mapeados 25 mulheres e 25 homens, cuja idade estimada variou de 3 a 75 anos. Tais usuários permaneceram na praça em média 18,3 minutos (de 40 segundos a 1:27 hora). Em todos os grupos, as mulheres permaneceram mais tempo na praça do que os homens da mesma idade. Entre os principais resultados obtidos com esta técnica destacam-se:

- Crianças - as atividades mais observadas foram brincar, jogar, passear e conversar, verificandose alguma diferença entre os gêneros; em sua principal atividade, as meninas passaram em média 19 minutos e os meninos 17,6 minutos; elas se envolveram mais em atividades como passear com cachorro, pular amarelinha e conversar e se concentraram nos St4 e St6; eles desempenharam predominantemente atividades dinâmicas como futebol, corre-corre e brincadeira na ATI, e se concentraram nos St3, 5, 6 e 10.
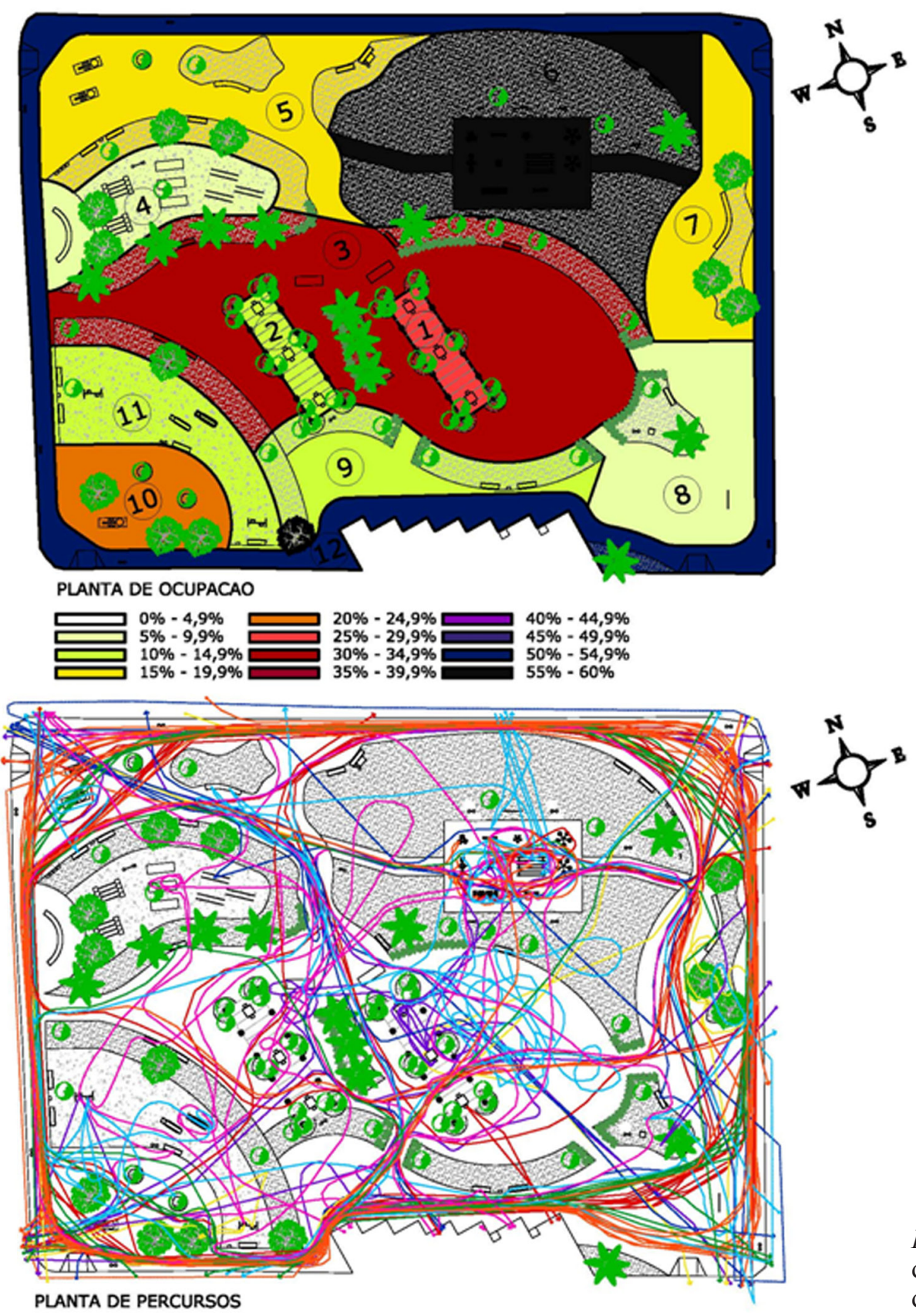

Figura 2. PKM - Planta de Ocupação do MCCLugar e Planta de Percursos do MCCPessoa. 
- Adolescentes - a maioria frequenta a PKM por volta das 12:00h (horário de saída das aulas) e a utilizou para passagem, embora também se verifiquem conversa (St7), brincadeira, hip hop (St10, 1 e 3) e descanso; as adolescentes permaneceram no local em média 20,3 minutos e os adolescentes, 7,5 minutos; o playground infantil (St11) foi bastante utilizado pelo grupo.

- Adultos - não usaram toda a praça; além da passagem (majoritária), foi frequente a atividade física, como ginástica (St6), corrida e caminhada (St4 e St12); as mulheres permaneceram na praça em média 18,5 minutos e os homens 4,4 minutos.

- Idosos - além de comportamento contemplativo, o grupo apresentou atividades semelhantes aos dos adultos, tendo predominado a caminhada no perímetro (St12), que pode somar-se à pratica de exercícios no St6 (ATI); elas passaram em média 9 minutos e eles 8,1 minutos no local; ressalte-se a grande interação entre idosos e adultos de ambos os gêneros (muitos dos quais aparentemente amigos ou familiares).

Complementando essa visão do uso, as entrevistas a 7 mulheres e 7 homens (equilibradas as faixas etárias) confirmaram o predomínio das atividades esportivas (citadas por 9 participantes), seguidas por atividades contemplativas (7 citações). Quando questionados sobre o que percebiam outros usuários fazerem naquele local, as respostas mais frequentes foram as atividades esportivas (14) e as brincadeiras (7). O lazer cultural e o contemplativo foram pouco mencionados.

Relatando seus motivos para gostar da praça, as pessoas destacaram o contato com a natureza, a fuga temporária da rotina cotidiana, ter um espaço próximo de casa para praticar exercícios sem pagar academia, observar (outras pessoas e o entorno) e entrar em contato com conhecidos e desconhecidos. Tais características são típicas dos ambientes restauradores (Alves, 2011; Korpela et al., 2010; Ryan et al., 2010), revelando: escape (procurar lugares diferentes do dia a dia), escopo (senso de pertença, sensação de estar em contato ou se dar conta do mundo ao redor), fascinação (sentirse atraído pelo lugar) e compatibilidade (congruência entre o que o ambiente oferece e o que a pessoa ali deseja realizar). Além disso, a diversidade de uso, as trocas sociais e culturais permitidas pelo convívio entre pessoas de diversas faixas etárias (mesmo sem muito contato direto) e até os conflitos detectados, mostram a vitalidade da PKM e confirmam aspectos relevantes sobre os ELPs comentados pela literatura (Active Living Research, 2010; Oliveira \& Mascaró, 2007; OPENspace Research Centre, 2010; Thompson \& Travlou, 2007).

\section{ESTUDO 2 - A SOCIALIZAÇÃO DE IDOSOS NA ATI}

Defendendo o Envelhecimento Ativo, a Organização Mundial da Saúde (WHO, 2003) aponta que idosos que permanecem apenas em casa estão mais propensos a, entre outros, depressão e problemas de mobilidade, indicando a importância da frequência a ELPs para manter sua saúde física e mental. Em vários países, os estudos mostram que a qualidade de vida dos idosos está associada às oportunidades oferecidas para que se exercitem, socializem e realizem atividades comunitárias, enfim, se mantenham ativos e independentes (Sugiyama \& Thompson, 2005). Para tanto, enfatizam o papel do suporte ambiental, entendido como conjunto de recursos que facilitam e apoiam as atividades dos usuários.

No Brasil, a Política Nacional do Idoso (Brasil, 1994) e o Estatuto do Idoso (Brasil, 2003) fomentaram iniciativas voltadas para essa faixa etária, como o Programa Brasil Saudável (Brasil, 2005) e a Política Nacional de Saúde da Pessoa Idosa (Brasil, 2006) que, entre outras, proporcionaram a implantação das Academias da Terceira Idade (ATI), conjunto com 10 equipamentos metálicos para a prática de exercícios físicos ao ar livre, que são movimentados pela força física do usuário, que controla o ritmo e a quantidade de repetições.

Partindo destas indicações, a tese de Silva (2014) investigou a associação entre os elementos do suporte ambiental e as interações sociais dos idosos, tendo realizado parte da pesquisa de campo na PKM apresentada nesse artigo como Estudo 2. O trabalho concentrou-se no St6 da pesquisa anterior, local que o mapeamento comportamental mostrou agregar a maior concentração de idosos e cujos principais elementos de suporte são a ATI, bancos e árvores.

\section{Método}

A investigação empregou: diário de campo do pesquisador, formulários para registro das características do suporte, entrevista semiestruturada e observação naturalística. Atendendo às exigências éticas, os participantes aceitaram participar de várias etapas de pesquisa durante a realização de seus exercícios diários e assinaram o TCLE.

\section{Principais resultados}

Constatou-se que o suporte ambiental da PKM oferece ao público idoso oportunidades para a realização de atividades variadas, com destaque para elementos ligados a: 
- Acessibilidade física (rampas de acesso, pisos íntegros, boa sinalização, legibilidade);

- Estrutura para permanência (bancos, mesas, iluminação noturna, sombreamento diurno);

- Estrutura para atividades (equipamento da ATI, aparelhos de ginástica tradicionais em concreto, espaço para caminhada, locais para atividades livres);

- Aprazibilidade (boa conservação, jardim, caramanchões, sensação de segurança).

A literatura indica que, nos ELPs, tais elementos são associados ao bem-estar e à qualidade de vida dos idosos que as frequentam, favorecendo diferentes níveis de engajamento (Barton, 2009; Sugiyama \& Thompson, 2005). Seus efeitos são traduzidos em benefícios fisiológicos (envolvimento em atividades físicas), psicológicos (sentimentos advindos do contato com elementos naturais e estéticos) e sociais (interação com amigos, vizinhos e outros).

$\mathrm{Na}$ PKM as interações sociais por meio da conversação ocorrem durante a caminhada, nos bancos sob a sombra e, sobretudo, no uso dos equipamentos da ATI (St6). Na caminhada elas ocorrem nos grupos que variam entre 2 a 4 pessoas, em geral casais ou pessoas com proximidade afetiva estabelecida por razões diversas, dentre as quais se figura a amizade surgida pelo próprio uso frequente da praça.

Na ATI, a distribuição espacial dos equipamentos facilita a interação, pois a distância entre eles permite a manutenção de tom de voz natural, sem interromper os exercícios, situação ainda mais favorável à socialização nos aparelhos usados simultaneamente por 2 ou mais pessoas posicionadas paralela ou frontalmente. Isso ocorre porque arranjos espaciais que possibilitam conversas laterais e frontais, além de permitir o diálogo, facilitam a leitura labial para pessoas com restrições auditivas (Dorneles, 2006). Apenas o equipamento remada sentada (Figura 1 E5) tem uso exclusivamente individual. O esqui (Figura 1-E7), o simulador de caminhada (Figura 1-E1) e o simulador de cavalgada (Figura 1-E10) possuem capacidade para 3 pessoas, distribuídas lado a lado. O alongador (Figura 1-E6), a pressão de pernas (Figura 1-E3), a rotação dupla diagonal (Figura 1-E8), a rotação vertical (Figura 1-E9) e o $\operatorname{surf}$ (Figura E4) recebem 2 ou 3 pessoas e permitem contato face à face. O multi-exercitador (Figura 1-E2) pode ser usado simultaneamente por 4 pessoas, sem contato visual lateral ou frontal (mas, mesmo sem contato visual direto, notamos haver comunicação).

Considerando o alto índice de socialização observado (em apenas 13,6\% os registros efetuados não houve interação entre idosos), nos interessamos pela temática das conversas desenvolvidas, que incluem assuntos relativos à saúde, alimentação, filhos, tratamentos médicos e passeios. Entre os homens os temas mais frequentes foram política, futebol e comentários humorísticos sobre a condição de ser velho. Entre as mulheres predominaram assuntos relacionados a acontecimentos pessoais e da vida cotidiana.

A entrevista mostrou que os idosos usuários residem nas imediações da PKM e sua frequência é diária. Inicialmente ela teria sido motivada pela instalação da ATI e a possibilidade de realizar atividades físicas gratuitas; atualmente o principal motivo é encontrar amigos. Os participantes percebem que a utilização do espaço ajuda a manter a saúde física e a diminuir as preocupações (por compartilhar suas dificuldades com os outros). Alguns deles habitam em bairros próximos, inclusive que possuem praças com ATI instalada, mas relataram preferir frequentar a PKM devido a: conviver com os amigos, sentir-se seguro, considerar o lugar bonito, notar que ali há um número maior de pessoas.

Essas constatações são compatíveis com os resultados obtidos por outros pesquisadores, os quais afirmam haver associação entre as formas de interação social e a prática de atividades, pois as primeiras estimulam os idosos a saírem de casa e a exercitarem suas habilidades, incitando-os a participarem de programas de qualidade de vida, atividades de lazer (jogos, danças), atividades comunitárias ou voluntárias, entre outras (Bennett, 2002; Butterworth, 2000; McAuley et al., 2000; Sugiyama \& Thompson, 2005).

\section{UM OÁSIS NA CIDADE}

Considerando que os comportamentos mapeados na PKM se voltam para descanso, bem-estar, prazer e recreação, podemos afirmar que o lazer é sua principal função. Nela, porém, os diversos tipos de lazer não acontecem na mesma proporção. As observações e as entrevistas confirmaram que o lazer esportivo tem destaque em relação aos demais, seguido pelo lazer ativo e pelo contemplativo. O lazer cultural é o menos frequente, porém mostra que a praça apresenta espaços multiuso que permitem versatilidade ocupacional. Podemos atribuir o destaque do lazer esportivo à presença da ATI, que estimula todos (não apenas os idosos) a se exercitarem, embora o uso dos equipamentos por crianças e adolescentes, geralmente para brincadeiras, não seja adequado, pois pode afetar seu funcionamento.

$\mathrm{Na}$ PKM as atividades de socialização são constantes, estimulando as pessoas a saírem de casa e a interagirem, o que tem importante papel na promoção/ manutenção de sua saúde física e funcionamento 
cognitivo (WHO, 2003), aumenta sua autoestima, ajuda a lidar com as dificuldades do cotidiano (Papalia \& Feldman, 2013; Ramos, 2002), favorece a promoção de um estilo de vida ativo, proporcionando bem-estar e melhoria na qualidade de vida (Active Living Research, 2010; Mahmood et al., 2012). Especificamente com relação ao idoso, a presença de um suporte ambiental eficiente facilita sua permanência e participação na vida comunitária (OPENspace Research Centre, 2010), indo ao encontro das prescrições da política nacional nesse campo (Brasil, 1994, 2003, 2005, 2006, entre outras).

Nesse sentido, a existência dos recursos no espaço da PKM contribui para as metas das políticas de promoção da saúde, bem-estar e qualidade de vida da comunidade que a utiliza. Em termos de design, observase que sua proposta define claramente áreas de lazer contemplativo (St5, St7, St8, St9 e St10), lazer ativo (St11), lazer esportivo (St4 e St6), convivência (St1 e St2), espaço multiuso (St3) e circulação (St12), porém, o MCCLugar e o MCCPessoa mostram que nem sempre os usos previstos para esses setores são realmente os mais frequentes. Tais alterações nos remetem ao conceito de affordances (Gibson, 1986; Günther, 2011), entendidas como possibilidades de ação latentes em um objeto ou local e decodificadas pelos usuários em função de suas necessidades. Diretamente ligadas às atividades do cotidiano, ao darem ao local e seus elementos um sentido diferente daquele originalmente projetado, as affordances implicam novos modos das pessoas se apropriarem do ambiente e, nesse sentido, estão relacionadas às características da cultura local, notadamente no que se refere a sua permissividade com relação a aceitação de novas práticas. São exemplos de affordances materializadas nos usos da PKM:

- Mesas e bancos apoiam manobras do hip hop, são obstáculos do skate, servem para trocar fraldas, engraxar sapatos, deitar, dormir, etc.;

- Pórticos e equipamentos do playground usados em escaladas de le parkour;

- Bancos, mesas e elementos verticais (pórticos e postes) funcionando como apoio para abdominais e alongamento de pernas;

- Canteiros transformados em tanques, utilizados pelos moradores de rua e catadores de lixo para lavar seus pertences e até tomar banho;

- Equipamentos em concreto destinados a abdominais usados como escorregadores e trepatrepa pelas crianças, bancos pelos adultos e adolescentes e desafios para le parkour;

- Equipamentos de ginástica da ATI servindo como brinquedos para as crianças e adolescentes, que os usam de modos variados/inusitados (subir, pendurar-se, esconder-se).
Objetos e locais que oferecem várias affordances tendem a ser mais utilizados, o que facilita o processo de apropriação e apego. Na PKM muitas das affordances observadas estão ligadas às atividades de lazer, contribuindo para o desenvolvimento psicomotor de quem delas usufrui (não apenas crianças) e influenciando a diversidade da ocupação do lugar na medida em que multiplicam as possibilidades de uso dos seus elementos físicos. Essa condição ajuda a consolidar o papel da PKM na dinâmica urbana e, no processo de retroalimentação projetual de ELPs, nos faz inferir a importância da proposição de ambientes que permitam multiuso, oferecendo elementos de suporte a diversas atividades.

\section{CONSIDERAÇÕES FINAIS}

No atual contexto das cidades brasileiras, o uso das praças é uma questão delicada, que se torna ainda mais complexa ao ser investigada a partir das interações pessoa-ambiente. Para tanto, a adoção de estratégia multimetodológica contribuiu significativamente para as duas pesquisas relatadas, pois a integração da observação comportamental às entrevistas e aos diários de campo dos pesquisadores permitiu maior compreensão dos comportamentos dos usuários, associando-os aos locais em que ocorrem e aos equipamentos usados. Esse aprofundamento rendeu boas reflexões sobre o lazer e a socialização em praças, contribuindo para o amadurecimento de nossas discussões e ampliando nossos olhares sobre as interfaces entre Psicologia Ambiental e Arquitetura e Urbanismo.

De modo geral a PKM é apreciada por seus frequentadores e pelos transeuntes. Seu uso é facilitado devido a: localização em área de uso misto; configuração espacial de fácil leitura; bom estado geral de conservação; existência de equipamentos destinados a diversas atividades e faixa etárias; fácil tráfego de pedestres nas ruas e calçadas circundantes; existência de controle social contínuo, porém não ostensivo, representado pelos "olhos" da vizinhança e dos funcionários contratados para limpar e regar. Sua ocupação começa logo cedo, para o lazer esportivo. No decorrer do dia, durante o horário comercial e com o aumento da incidência solar, a quantidade de usuários diminui, voltando a aumentar no final da tarde. À noite o movimento é reduzido, mas os vestígios comportamentais mostram que, mesmo de madrugada, há atividade no local. Na praça o lazer acontece de modo variado, havendo atividades que ocorrem com mais frequência e outras esporádicas. Os esportes são estimulados pela presença de calçada plana, bem 
conservada e livre de obstáculos, da ATI e de pessoas de várias idades. Os jovens se dedicam mais ao lazer ativo e a conversa; os adultos e idosos preferem o lazer esportivo e o contemplativo. As brincadeiras infantis e a prática de le parkour, as manobras de skate e o hip-hop dos adolescentes denotam a atualidade do uso. Observa-se, ainda, que, embora convivam bem entre si, os grupos de diversas faixas etárias não se misturam, tanto devido aos diferentes interesses quanto por motivos de segurança.

Especialmente em relação aos idosos, além de ambiente restaurador, a PKM contribui para seu envelhecimento ativo e, mais do que exercícios, a ATI atua em sua socialização, tornando-se aliada, portanto, da política nacional de atenção ao idoso.

Assim, fugindo do quadro pessimista de abandono dos ELPs existente na contemporaneidade, a PKM se abre para receber a população, oferecendo uma mistura de setores sombreados e ensolarados, regiões reservadas que permitem privacidade, áreas para reunião de pessoas e equipamentos que propiciam diferentes affordances. O sucesso de seu uso para lazer e socialização está associado à diversidade de ambientes e de suporte para as atividades nelas previstos, mas também à cultura local que, a seu modo, ajuda estas pessoas e suas atividades a conviverem. A maneira como diferentes grupos de pessoas se apropriam daquele espaço e o (re)significam, dando-lhe um uso e um sentido mais amplo do que aquele instrumentalmente projetado em sua origem, configura-se como uma diversidade que se reflete em vitalidade urbana, correspondendo, em síntese, ao que buscamos para nossas cidades.

As investigações também permitiram identificar pontos que podem ser corrigidos para tornar a PKM um local melhor e beneficiar novos projetos. Com relação ao último ponto é possível sugerir que no planejamento de praças é essencial inserir elementos que ofereçam suporte às atividades dos usuários, como arborização/ sombreamento, segurança e estrutura para a prática de diversas modalidades de lazer, incorporando caráter lúdico e recreativo. Além disso, a participação/ envolvimento da comunidade no projeto/execução/ manutenção das praças certamente irá agregar maior sucesso a esse tipo de empreendimento. Possibilitando a criação de espaços propícios ao encontro e a socialização dos usuários das adjacências (pessoas da comunidade, estudantes ou trabalhadores), tais medidas reforçariam laços sociais, promoveriam apego ao lugar (place attachment) e favoreceriam a identidade do lugar, com repercussão positiva no bem-estar individual e no convívio coletivo.

Finalmente, impõe-se uma ressalva quanto à generalização dos resultados destes dois estudos.
Embora a indicação de aspectos que favorecem o lazer na PKM possa ser semelhante a de outros empreendimentos do gênero, é essencial ressaltar que cada ambiente guarda suas singularidades, isto é, cada praça possui características socioambientais específicas (história, elementos físicos e climáticos, presença/ausência de natureza e equipamentos, estilos de vizinhança, origem e hábitos dos usuários/frequentadores, etc.) que irão favorecer/inibir comportamentos diversos. Logo, a transposição dos resultados pode não ser adequada a outros contextos, só devendo ser feita de modo criterioso e mediante novas pesquisas.

\section{REFERÊNCIAS}

Active Living Research. (2010). The Economic Benefits of Open Space, Recreation Facilities and Walkable Community Design. San Diego: Robert Wood Johnson Foundation.

Alex, S. (2008). Projeto da Praça: convívio e exclusão no espaço público. São Paulo: Senac.

Alves, S. M. (2011). Ambientes restauradores. In S. Cavalcante \& G. A. Elali (Orgs.). Temas básicos em Psicologia Ambiental (pp. 44-52). Petrópolis, RJ: Vozes.

Andrade, L. T., Jayme, J. G., Almeida, R. C. (2009). Espaços públicos: novas sociabilidades, novos controles. Cadernos Metrópole (São Paulo), 21(1), 131-153.

Barton, H. (2009). Land use planning and health and wellbeing. Land Use Policy, 26 (Supplement 1), S115-S123. DOI: 10.1016/j.landusepol.2009.09.008.

Bennett, K. M. (2002). Low level social engagement as a precursor of mortality among people in later life. Age and Ageing, 31(3), 165-168. DOI: 10.1093/ageing/31.3.165.

Brasil. Ministério da Saúde (1994). Lei 8.842, de 04 de janeiro de 1994 - Dispõe sobre a Política Nacional do Idoso (PNI), cria o Conselho Nacional do Idoso e dá outras providências. Disponível em: http://direitodoidoso.braslink.com/05/lei8842. html

Brasil. Ministério da Saúde (2003). Lei 10.741 de $1^{\circ}$ de outubro de 2003 - Dispõe sobre o Estatuto do Idoso e dá outras providências. Disponível em: http://direitodoidoso.braslink.com/05/estatuto_ do_idoso.pdf

Brasil. Ministério da Saúde (2005). Programa Brasil Saudável. Disponível em: http://direitodoidoso.braslink.com/05/programa_ brasil_saudavel.pdf.

Brasil. Ministério da Saúde (2006). Portaria $n^{\circ} 2.528$ de 19 de outubro de 2006 - Aprova a Política Nacional de Saúde da Pessoa Idosa. Disponível em: http://direitodoidoso.braslink. com/05/portaria_2528.pdf

Butterworth, I. (2000). The relationship between the built environment and wellbeing: a Literature Review (T. B. E. a. Wellbeing, Trans.) The Built Environment and Wellbeing (pp. 46). Melbourne, Au.

Camargo, L. O. L. (2008). O que é Lazer. São Paulo: Brasiliense.

Cotrim, G. S. \& Bichara, I. D. (2013). Brincar no ambiente urbano: limites e possibilidades em ruas e parquinhos de uma metrópole. Psicologia, Reflexão e Crítica (Porto Alegre), 26(2), 388-395.

Dumazedier, J. (2004). Lazer e cultura popular. São Paulo: Perspectiva.

Dorneles, V. G. (2006). Acessibilidade para idosos em áreas livres públicas de lazer. Dissertação de Mestrado, Programa de PósGraduação em Arquitetura e Urbanismo, Universidade Federal de Santa Catarina, Florianópolis. 
Gehl, J. (2007). Public spaces for a changing public life. In C. W. Thompson \& P. Travlou (Orgs.). Open Space: People Space (pp. 3-7). New York: Taylor \& Francis.

Gibson, J. J. (1986). The Ecological Approach to Visual Perception. Hillsdale, New Jersey: Lawrence Erlbaum Associates.

Gomes, M. A. S. (2007). De Largo a Jardim: Praças Públicas no Brasil - Algumas Aproximações. Estudos Geográficos, 5(1), 101-120.

Günther, H. (2011). Affordances. In S. Cavalcante \& G. A. Elali (Orgs.). Temas básicos em Psicologia Ambiental (pp. 21-27). Petrópolis, RJ: Vozes.

Günther, H., Elali, G. A., \& Pinheiro, J. Q. (2011). Multimétodos. In S. Cavalcante \& G. A. Elali (Orgs.). Temas básicos em Psicologia Ambiental (pp. 239-249). Petrópolis, RJ: Vozes.

Günther, I. O uso da entrevista na interação pessoa-ambiente. (2008). In J. Q. Pinheiro \& H. Günther (Orgs.). Métodos de pesquisa nos estudos pessoa-ambiente (pp. 53-74). São Paulo: Casa do Psicólogo.

Hino, A. A. F., Reis, R. S., Ribeiro, I. C., Parra, D. C., Brownson, R. C., \& Fermino, R. C. (2010). Using Observational Methods to Evaluate Public Open Spaces and Physical Activity in Brazil. Journal of Physical Activity and Health, 7(2), S146-S154.

IDGO - Inclusive Design for Getting Outdoors. (2010). A built environment for all ages. Paper presented at the Extending Quality Life for older and disabled people. Disponível em: http//:www.idgo.ac.uk/

Jacobs, J. (1961). The Death and Life of Great American Cities. New York: Vintage Books.

Kaplan, R., Kaplan, S. \& Ryan, R. L. (1998). With people in mind: design and management of everyday natures. Washington, DC: Island Press.

Korpela, K. M., Ylén, M., Tyrväinen, L., \& Silvennoinen, H. (2010). Favorite green, waterside and urban environments, restorative experiences and perceived health in Finland. Health Promotion International, 25(2), 200-209. DOI: 10.1093/heapro/daq007

Liberalino, C. C. (2011). Praça: lugar de lazer: relações entre características ambientais e comportamentais na Praça Kalina Maia - Natal RN. Dissertação de Mestrado, Programa de PósGraduação em Psicologia, Universidade Federal do Rio Grande do Norte, Natal.

Luz, G. M. \& Kuhnen, A. (2013). O uso dos espaços urbanos pelas crianças: explorando o comportamento do brincar em praças públicas. Psicologia, Reflexão e Crítica (Porto Alegre), 26(3), 552-560.

McAuley, E., Blissmer, B., Marquez, D. X., Jerome, G. J., Kramer, A. F., \& Katula, J. (2000). Social relations, physical activity, and well-being in older adults. Preventive Medicine, 31(5), 608-617. DOI: 10.1006/pmed.2000.0740.

Mahmood, A., Chaudhury, H., Michael, Y. L., Campo, M., Hay, K., \& Sarte, A. (2012). A photovoice documentation of the role of neighborhood physical and social environments in older adults' physical activity in two metropolitan areas in North America. Social Science \& Medicine, 74(8), 1180-1192. DOI: 10.1016/j. socscimed.2011.12.039

Mira, R. G. \& A. Dumitru, A. (2014) Urban sustainability: innovative spaces, vulnerabilities and opportunities. A Coruña: IAPS.

Mourão, A. R. T. \& Cavalcante, S. (2011). Identidade de lugar. In S. Cavalcante \& G. A. Elali (Orgs.). Temas básicos em Psicologia Ambiental (pp. 208-226). Petrópolis, RJ: Vozes.

Oliveira, L. A. \& Mascaró, J. J. (2007, abril/junho). Análise da qualidade de vida urbana sob a ótica dos espaços públicos de lazer. Ambiente Construído, 7(2), 59-69.

OPENspace Research Centre. (2010). Community Green: using local spaces to tackle inequality and improve health. England: CABE.
Papalia, D. E. \& Feldman, R. D. (2013). Desenvolvimento humano (12 ${ }^{\mathrm{a}}$ ed.). Porto Alegre: ArtMed.

Petroski, E., Silva, D., Reis, R., \& Pelegrini, A. (2009). Estágios de mudança de comportamento e percepção positiva do ambiente para atividade física em usuários de parque urbano. Motricidade, $5(2), 17-31$

Pinheiro, J. Q., Elali, G. A., \& Fernandes, O. S. (2008). Observando a interação pessoa-ambiente: vestígios ambientais e mapeamento comportamental. In J. Q. Pinheiro \& H. Günther (Orgs.). Métodos de Pesquisa nos Estudos Pessoa-Ambiente (pp. 75-104). São Paulo: Casa do Psicólogo.

Ramos, M. P. (2002). Apoio social e saúde entre idosos. Sociologias, 4(7), 20.

Robba, F. \& Macedo, S. S. (2003). Praças Brasileiras. São Paulo: Edusp.

Ryan, R. M., Weistein, N., Berstein, J., Brown, K. W., Mistretta, L., \& Gagné, M. (2010). Vitalizing effects of being outdoors and in nature. Journal of Environmental Psychology, 30(2), 159-168. DOI: 10.1016/j.jenvp.2009.10.009

Silva, E. A. R. (2014). O papel das interações sociais para o envelhecimento ativo: um estudo em praças natalenses. Tese de Doutorado, Programa de Pós-Graduação em Psicologia, Universidade Federal do Rio Grande do Norte, Natal.

Silva, G. C., Lopes, W. G. R., \& Lopes, J. B. (2009). Aspectos relacionados ao uso e apropriação de praças em áreas centrais de cidades: transformações e permanências. RA'EGA, 18(1), 59-78.

Sommer, R. \& Sommer, B. (2002). A Practical Guide to Behavior Research, Tools and Techniques. Nova York: Oxford University Press.

Sugiyama, T. \& Thompson, C. W. (2005). Environmental Support for Outdoor Activities and Older People's Quality of Life. Journal of Housing for the Elderly, 193(4), 18. DOI: 10.1300/ J081v19n03 09

Sugiyama, T., Thompson, C. W., \& Alves, S. (2009). Associations Between Neighborhood Open Space Attributes and Quality of Life for Older People in Britain. Environment and Behavior, 41, 18. DOI: $10.1177 / 0013916507311688$

Thompson, C. W. (2007). Playful nature. In C. W. Thompson \& P. Travlou (Orgs.). Open Space: People Space (pp. 26-37). New York: Taylor \& Francis.

Thompson, C. W. \& Travlou, P. (2007) (Orgs). Open Space: People Space. Oxon: Taylor \& Francis.

Tuan, Yi-fu (1983). Espaço e lugar: a perspectiva da experiência. São Paulo: DIFEL.

WHO, World Health Organization. (2003). Health and development through physical activity and sport move for health. Geneva, Switzerland: World Health Organization.

Woolley, H. (2005). Urban Open Spaces. London: Spon Press (Taylor and Francis Group).

\footnotetext{
Autores: Grande do Norte. Rio Grande do Norte. Norte.

Endereço para correspondência:

Cíntia Camila Liberalino Viegas

Rua Severina Ferreira de Medeiros, 14 - Capim Macio

59082-340 Natal, RN, Brasil

E-mail: 8cintiacamila8@gmail.com

Recebido em: 28.05 .2014

Aceito em: 11.08.2014
}

Cíntia Camila Liberalino Viegas - Doutorando, Universidade Federal do Rio

Eduardo Alexandre Ribeiro da Silva - Doutorando, Universidade Federal do

Gleice Azambuja Elali - Doutor, Universidade Federal do Rio Grande do 